\title{
Integration of tree allometry rules to treetops detection and tree crowns delineation using airborne lidar data
}

\author{
Ivan Sačkov ${ }^{(1)}$, \\ Tomáš Hlásny ${ }^{(1-2)}$, \\ Tomáš Bucha ${ }^{(1)}$, \\ Miroslav Juriš ${ }^{(3)}$
}

\begin{abstract}
Airborne laser scanning (ALS) has recently gained increasing attention in forestry, as ALS data may facilitate the efficient assessment of forest inventory attributes and ecological indicators related to forest stand structure. This paper presents a novel workflow for individual tree detection and tree crown delineation using ALS data. The developed point-based approach included several tree allometry rules on permissible tree heights and crown dimensions to increase the likelihood of detecting the actual tree profiles. The accuracy of the method was assessed in a heterogeneous forest with a complex stand structure in Slovakia (Central Europe). ALS measurements were taken using a RIEGL Q680i scanner at $700 \mathrm{~m}$ of height with a point density of 20 echoes per $\mathrm{m}^{2}$. The ground reference data included the measured positions and dimensions of 1332 trees in nine plots distributed across the region. We found that the number of individual trees detected by the algorithm using ALS data was systematically underestimated by $34 \pm 15 \%$ relative to the reference data. The delineated crown coverage was underestimated by $2 \pm 6 \%$ as well, but the latter difference was not statistically significant $(p>0.05)$.
\end{abstract}

Keywords: Tree Allometry, Airborne Laser Scanning, Individual Tree Detection, Point-based Approach

\section{Introduction}

In recent years, airborne laser scanning (ALS), also referred to as airborne light detection and ranging (LiDAR), has become established as a novel technology for estimating forest inventory attributes (e.g., tree or stand height and diameter, basal area, volume - Hyyppä \& Inkinen 1999, Mikita et al. 2013). The capability of ALS to penetrate tree crowns enables the collection of data on tree and stand characteristics that would otherwise require on-site measurement (Sheridan et al. 2015). Moreover, the recognition that stand structural diversity has a positive effects on the quality of most ecosystem services has further fostered the application of new remote sens ing approaches to stand-structure mapping (Bottalico et al. 2014). In general, there are two broad groups of forest inventory methods based on ALS data: area-based

approaches (ABA) and individual tree detection approaches (ITD).

The area-based prediction of forest attributes relies on the statistical dependency between the field-measured and ALSderived variables (Maltamo et al. 2007), i.e., forest attributes are regressed against the ALS-derived metrics. Such statistical relationships can be approximated using linear models (Means et al. 2000), non-parametric approaches including nearest-neighbors imputation (Andersen et al. 2011), linear mixed effects models with random stand-level intercepts (Vauhkonen et al. 2011a) or Bayesian methods (HernandezMarin et al. 2007). ABA methods have been used to assess forest attributes for nearly 20 years (Naesset 1997, Hyyppä et al. 2007, $\mathrm{Xu}$ et al. 2014), though their reliability in terms of information on tree species, tree size distribution and the number of trees $\square$ (1) National Forest Centre - Forest Research Institute Zvolen, T. G. Masaryka 22, Zvolen, 96092 (Slovakia); (2) Czech University of Life Sciences Prague, Faculty of Forestry and Wood Sciences, Kamýcká 129, 16521 Prague 6 (Czech Republic); (3) National Forest Centre - Institute for Forest Resources and Information Zvolen, Sokolská 2, Zvolen, 96052 (Slovakia)

@ Ivan Sačkov (sackov@nlcsk.org)

Received: Apr 25, 2016 - Accepted: Jan 16, 2017

Citation: Sačkov I, Hlásny T, Bucha T, Juriš M (2017). Integration of tree allometry rules to treetops detection and tree crowns delineation using airborne lidar data. iForest 10: 459467. - doi: 10.3832/ifor2093-010 [online 2017-04-04]

Communicated by: Davide Travaglini still remains limited (Hollaus et al. 2014).

ITD methods involve a sequence of steps that includes tree detection, feature extraction, and estimation of tree attributes (Vauhkonen et al. 2014). Direct detection of individual trees and assessment of tree heights usually involves a raster-based or point-based techniques (Packalén \& Maltamo 2007, Lindberg \& Hollaus 2012), whereas tree or stand parameters are usually inferred indirectly (Tuominen et al. 2014). For example, tree or stand diameters are estimated based on tree height, crown size or stem density using allometric models, geometrically weighted regression methods (Salas et al. 2010) or various nonparametric approaches (Packalén \& Maltamo 2008). The precision of estimates of tree and stand volume, which are the primary variables of forestry interest, ultimately depends on the accuracy of the underlying characteristics, and is affected by the accumulation of both detection and estimation errors (Maltamo et al. 2009). Although numerous tree-level algorithms have been reported in the literature, their accuracy is still inadequate for ITD methods to be applied in forest inventories (Vauhkonen et al. 2014).

Many approaches have been developed to detect individual trees based on ALS data. Overviews were provided by Vauhkonen et al. (2011b), Kaartinen et al. (2012), Koch et al. (2014), and Eysn et al. (2015). Typically, the smoothed canopy height models (CHM) or laser point clouds are used for local maxima detection and expansion (Koch et al. 2006, Zhang et al. 
2015), watershed-based delineation (Yao et al. 2014) and point-cloud clustering (Pirotti 2010, Gupta et al. 2010). Hybrid techniques that combine the ALS data with different kinds of geo-data and a variety of a priori information are also used (Heinzel et al. 2010, Lähivaara et al. 2014). A promising solution for improving tree detection accuracy is based on the use of tree allometry. For example, the region-growing algorithm by Tiede \& Hoffmann (2006) stops the tree detection process based on the minimal height and maximal permissible width of a tree crown. Ene et al. (2012) proposed to use the area-based estimate of stem number for optimizing the $\mathrm{CHM}$ resolution and filter size. Swetnam \& Falk (2014) included a rule based on the expected canopy radius in the treetop detection algorithm that prevents branches of a single tree crown to be classified as local maxima, which usually reflect the treetops.

The comparability of accuracy assessments conducted under different conditions is limited. However, it has been suggested that the extraction method from ALS data is the main factor affecting the accuracy of tree detection, while point cloud density has a lesser impact (Kaartinen \& Hyyppä 2008). Plot size may also affect the accuracy of estimates of forest structure attributes. In particular, larger plots can increase the accuracy since the edge effect and co-registration errors are significantly reduced as compared with smaller plots (Frazer et al. 2011, Ruiz et al. 2014). Research has also suggested that accuracy of tree detection in terms of the relative root mean square error (RMSE\%) is in the range of $32-89 \%$ and the detection rate is in the range of $40-93 \%$.

The aim of this paper is to present a point-based workflow for detecting individual trees and delineating their crowns based on ALS data. The proposed algorithm attempts to improve several shortcomings of the current extraction methods through the following steps:

- the algorithm uses the complete information contained in ALS data in all procedures of tree detection workflow, and optimizes the computationally demanding operations by tiling and thinning techniques applied on the raw ALS data;

- treetops detection and tree crowns delineation is done iteratively, and each iteration includes tests for treetop identification based on tree allometry rules, aiming to ensure that the permissible spatial and the dendrometric structure of a forest stand and a tree are not violated, and that the likelihood of falsely identified trees is reduced;

- users can modify a number of parameters and customize the algorithm for matching specific stand conditions and/or meeting specific objectives.

The presented algorithm is implemented in the reFLex (remote Forest Land explorer) software, which was developed by the National Forest Centre, Slovakia. The objective was to develop an easy-to-use application to be employed in the forestry practice.

\section{Materials and methods}

\section{Algorithm description}

The algorithm for treetop detection and tree crown delineation includes five connected procedures which are described in detail in the following sub-chapters.

The input file is a classified point cloud containing ground and vegetation classes. The initial procedures are applied to: (i) divide the points into a 3 -dimensional regular tiles (Tiling procedure); (ii) calculate the absolute height above ground for each point (Normalization procedure); and (iii) reduce the number of points in the input file by applying a minimum tree height threshold (Height restriction procedure). These operations yield a point cloud that is further used for an iterative search of treetops and tree crowns (Finding the local maxima, Geo-Dendrometric test, Delineation of tree crowns). Finally, the outputs of all procedures are exported to point and polygon vector files in the ESRI shape (shp) format.

\section{Point cloud tiling and normalization}

The tiling procedure is used to divide the raw point cloud to a regular 3-dimensional tiles. This procedure is applied to efficiently use the computer memory and allow for parallel processing of points allocated to the tiles. The user-defined tile size (TS) is a variable that can significantly affect output accuracy.

The normalization of raw point cloud was applied to calculate the absolute height above ground $\left(h_{n o r}\right)$ for each point in each tile (eqn. 1):

$$
h_{\text {nor }}=z_{\max }-z_{\min }
$$

where $h_{\text {nor }}$ is the normalized height of points in the tile (in $\mathrm{m}$ ), $z_{\max }$ is the elevation of points in the tile ( $m$ a.s.l.), $z_{\min }$ is the elevation of the lowest point in the tile interpolated from the three adjacent tiles ( $m$ a.s.l.).

\section{Height restriction}

The height restriction procedure defines the minimal height $(\mathrm{m})$ of trees to be identified, thereby all points below this threshold are discarded. This operation reduces the initial number of points and the required computation time, and defines a shortest tree to be identified in the next steps.

\section{Finding the local maxima}

A moving-window analysis (Frank 2005, Longley et al. 2005) is applied to search iteratively for local maxima (as presumed treetops) in the processed point cloud. The search is performed in an area covering eight neighboring tiles (fewer at edge locations). The detected local maxima are referred to as the theoretical treetops $\left(T_{\text {teo }}\right)$, and then subjected to a geo-dendrometric (GD) test.

\section{Geo-dendrometric test}

As part of the local maxima detected in the previous operation might not be indicative of true treetops, an additional test is applied to select a subset of $T_{\text {teo }}$ that is considered to include the real treetops. We conceived a set of dendrometric criteria which define a permissible tree and stand structure in terms of tree distribution, height relationships between trees, and the relationship between tree height and crown dimensions. The values of such criteria can be derived from ground-sample data collected in the evaluated area or taken from literature on tree allometry. The $T_{\text {teo }}$ that pass the GD test conditions are referred to as true treetops $\left(T_{\text {true }}\right)$. The remaining $T_{\text {teo }}$ become false treetops $\left(T_{\text {false }}\right)$ and are processed along with the remaining points in a cloud in the next operations of the workflow. The GD test consists of the following steps:

(a) Testing for height differences between trees. A circular test area with radius that approximates the ratio of mean crown radius to tree height in the stand $\left(\mathrm{Cr}_{\text {mean }}\right)$, is created around each $T_{\text {teo }}$ (Fig. 1a), and the presence of other $\mathrm{T}_{\text {teo }}$ within the test area is evaluated. The size of the test area $r_{\lim }$ $(\mathrm{m})$ is defined as (eqn. 2 ):

$$
r_{\text {lim }}=T h_{\text {teo }} \cdot c r_{\text {mean }}
$$

where $T h_{\text {teo }}$ is the tree height of the theoretical top $(\mathrm{m})$, and $\mathrm{Cr}_{\text {mean }}$ is a user-defined estimate of the ratio of mean crown radius to tree height in the investigated forest. If no additional $T_{\text {teo }}$ occurs at a distance $<r_{\text {lim }}$, such $T_{\text {teo }}$ is accepted as a real treetop and is maked $\mathrm{T}_{\text {true }}$ (Fig. 1b). Contrastingly, when others $T_{\text {teo }}$ occur within the $r_{\text {lim }}$, such $T_{\text {teo }}$ are marked as $T_{\text {test }}$ and tested for height differences (Fig. 1C). The rationale underlying this test is that if the heights between the two tested $\mathrm{T}_{\text {teo }}$ are convex, such $\mathrm{T}_{\text {teo }}$ represent two treetops. In the opposite case, the lower $\mathrm{T}_{\text {teo }}$ is discarded, and only the higher $\mathrm{T}_{\text {teo }}$ is marked as a real treetop, while the discarded $\mathrm{T}_{\text {teo }}$ is considered as a part of crown of the higher $T_{\text {teo. }}$. To decide which $T_{\text {test }}$ in the tested pairs is the real treetop, the normalized heights $\left(\mathrm{h}_{\mathrm{T} \text {.nor }}\right)$ connecting the respective pair of $T_{\text {test }}$ are evaluated (Fig. 2a). The next step requires a customized value that approximates the ratio of mean tree height differences to tree height in the investigated forest $\left(h d_{\text {mean }}\right)$. Then, the limit $h_{\text {lim }}(m)$ is calculated for each lower $T_{\text {test }}$ as (eqn. 3 ):

$$
h_{\text {lim }}=T h_{L . t e s t}-\left(T h_{L . t e s t} \cdot h d_{\text {mean }}\right)
$$

where $h_{\text {lim }}$ is the limit of the test $(m)$, Th $h_{\text {L.test }}$ is the tree height of the lower tested top (m) and $h_{\text {mean }}$ is the estimate of the ratio of mean tree height differences to tree height in the investigated forest. 
Finally, if at least one $h_{T \text {.nor }}$ between the evaluated pair of $T_{\text {test }}$ is below $h_{\text {lim }}$, both tested $T_{\text {test }}$ are accepted as real treetops (Fig. 2b). In the opposite case, only the higher $\mathrm{T}_{\text {test }}$ is considered as a real treetop (Fig. 2c).

(b) Test of the horizontal and vertical distance between trees. The horizontal distance between trees is calculated in order to discard false treetops situated in the crowns of other trees. First, the distance to the closest $T_{\text {true }}$ is calculated for all new $T_{\text {test }}$ (i.e., those appearing in the second and subsequent iterations of the mowing-window-based search for the local maxima Fig. 3a). The next step requires the maximum permissible crown width $\left(\mathrm{Cw}_{\max }-\right.$ crown width expressed as a proportion of tree height) to be customarily established for the investigated forest. Then, the limit $d_{\lim }(m)$ is calculated for each $T_{\text {true }}$ (eqn. 4$)$ :

$$
d_{\lim }=T h_{\text {true }} \cdot c w_{\max }
$$

where $d_{\text {lim }}$ is the limit of the test $(m)$, Th true is the tree height of the true top $(\mathrm{m}), \mathrm{CW}_{\max }$ is the estimate of the ratio of maximum crown diameter to tree height in the evaluated forest. The test assumes that no treetop is allowed to occur within the distance $\mathrm{d}_{\lim }$ around any $\mathrm{T}_{\text {true }}$. The case of trees growing in the understorey is described below.

The vertical distance between trees is tested to discard false treetops situated in the crowns of other trees, and to capture the trees situated under the canopy. The

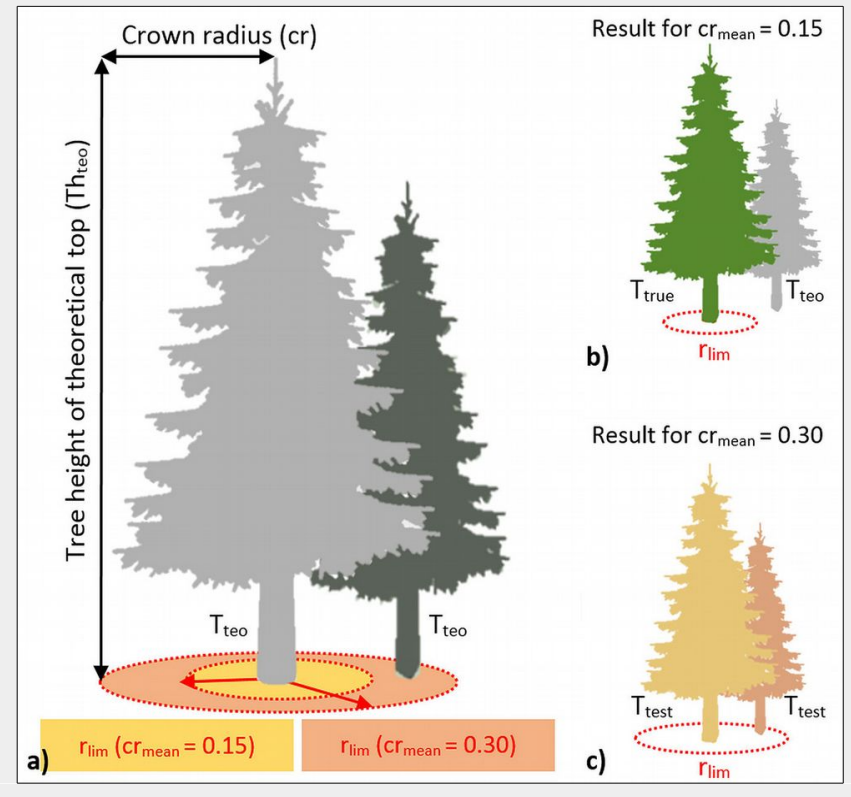

Fig. 1 - (a) Test for height difference between trees: a testing area $\left(r_{\text {lim }}\right)$ is created around each theoretical treetop ( $T_{\text {teo, }}$, grey trees) with radius equal to the ratio of mean crown radius to tree height in the investigated forest ( $\mathrm{Cr}_{\text {mean }}, 0.15$ or 0.3 of tree height in the example); (b) If only one $T_{\text {teo }}$ is found in the $r_{\text {lim }}$, it is marked as real treetop ( $\mathrm{T}_{\text {true, }}$ green tree); (c) otherwise, all co-occurring $T_{\text {teo }}$ are marked as testing tops ( $T_{\text {test}}$, brown trees).

test requires the user to specify the maxi- top can occur under the crown of any $T_{\text {true }}$ mum crown length in the investigated for- (Fig. 3b, Fig. 3c). est, in terms of crown length proportion of tree height $\left(\mathrm{cl}_{\max }\right)$. Then, the limit $\mathrm{I}_{\lim }(\mathrm{m})$ is calculated for each $\mathrm{T}_{\text {true }}$ (eqn. 5):

$$
l_{\text {lim }}=T h_{\text {true }}-\left(T h_{\text {true }} \cdot c l_{\text {max }}\right)
$$

where $\mathrm{I}_{\text {lim }}$ is the limit of the test $(\mathrm{m}), \mathrm{Th}_{\text {true }}$ is the tree height of the true top $(\mathrm{m}), \mathrm{Cl}_{\max }$ is the estimate of the ratio of maximum crown length to tree height in the investigated forest. This test assumes that a tree-

\section{Delineation of tree crowns}

Each $T_{\text {true }}$ is assigned to its central crown part (CCP), which is a circle of diameter equal to the tile size (TS). Then, the peripheral crown parts (PCP) of the point cloud are repeatedly assigned to the nearest CCP until they meet any point already assigned to any other CCP or until they reach the limits for assigning new crown parts (described below). A height limit ensures that

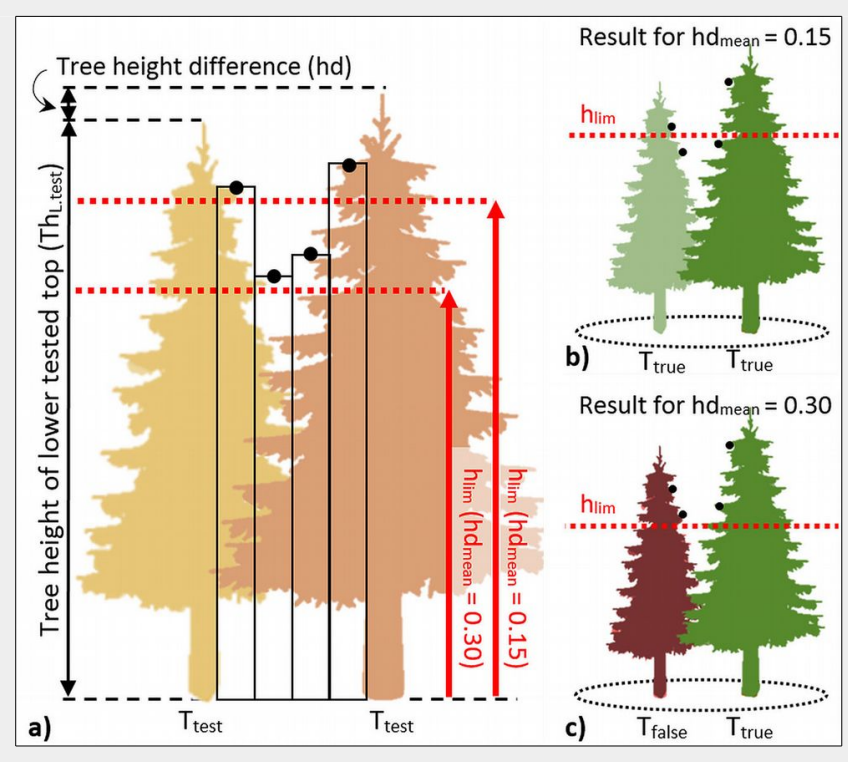

Fig. 2 - Test for height difference between trees (second part). (a) The normalized heights $h_{T \text {.nor }}$ (black points) between the pairs of $T_{\text {test }}$ are calculated using the point cloud data. Then, the height difference limit $h_{\text {lim }}$ is calculated for the lower $T_{\text {test }}$ in each pair of $\mathrm{T}_{\text {test }}$ (light brown tree). The limit depends on the ratio of mean tree height differences to tree height in the stand ( $\mathrm{hd}_{\text {mean }}, 0.15$ and 0.3 in the example); (b) If any $\mathrm{h}_{\mathrm{T} \text {.nor }}$ is lower than the $h_{\text {lim }}$, the $T_{\text {test }}$ is marked as real treetop ( $T_{\text {true, }}$ green trees); (c) otherwise, $T_{\text {test }}$ is marked as false treetop ( $\mathrm{T}_{\text {false }}$, dark brown tree).

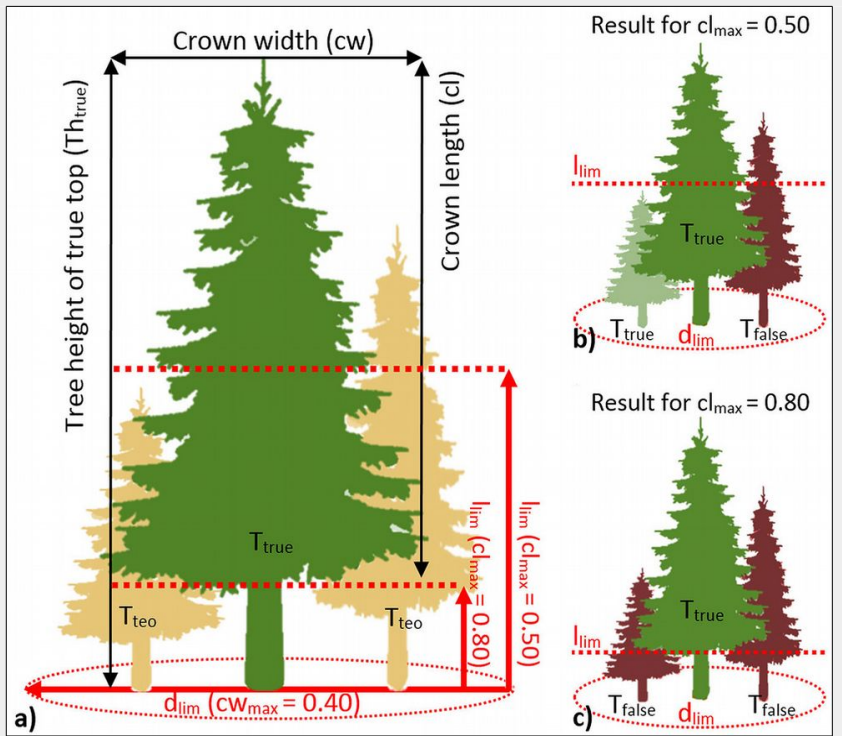

Fig. 3 - Tests of horizontal and vertical distance between trees are performed simultaneously to remove the theoretical treetops in locations where treetops are not expected to exist. (a) A horizontal limit $\mathrm{d}_{\lim }$ is calculated for each treetop $T_{\text {true }}$ to represent a maximum permissible crown width in the stand $\left(\mathrm{cW}_{\max }, 0.4\right.$ of tree height in the presented example). A vertical limit $\mathrm{I}_{\text {lim }}$ is calculated to define a maximum permissible tree length $\left(\mathrm{Cl}_{\max }, 0.5\right.$ and 0.8 of tree height in the presented example); (b, c) Then, all tested treetops $\left(T_{\text {test }}\right)$ are classified as either new real treetops $\left(T_{\text {true }}\right)$ or false treetops $\left(T_{\text {false }}\right)$. 


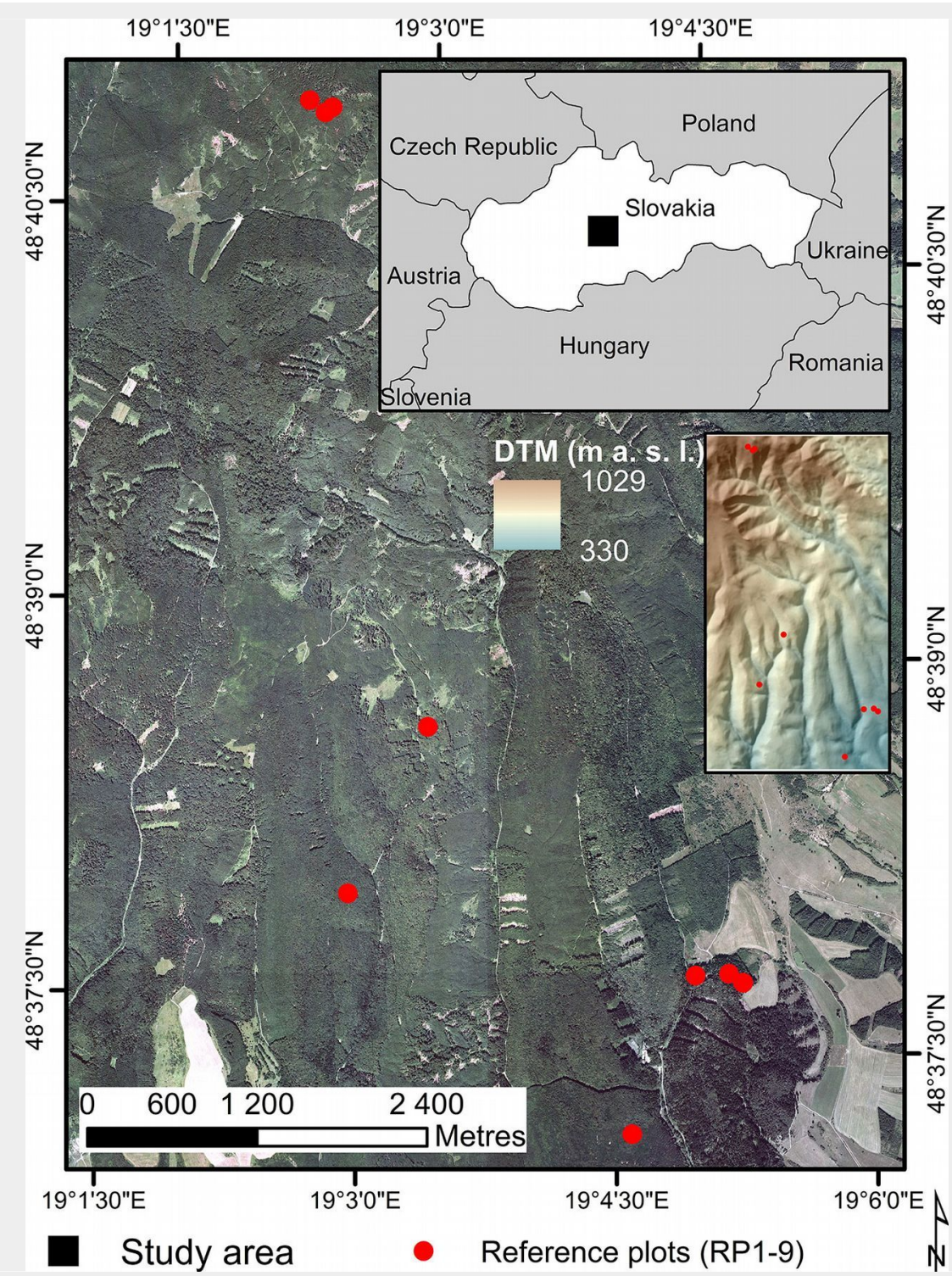

Fig. 4 - The study area. Elevation and position of the surveyed reference plots (RP1$\mathrm{RP9}$ ) are indicated by red circles on the maps.

all PCP which are to be assigned to the CCP are lower than $\mathrm{T}_{\text {true }}$ and in the height range specified by the crown length limit $\left(I_{\text {lim }}\right)$. Distance limit ensures that PCP is situated within the permissible width range specified by the crown distance limit $\left(\mathrm{d}_{\lim }\right)$. The information on the horizontal and vertical positions of all tested PCP is obtained from the point cloud data.

Finally, all parts of the crown (central and peripheral) assigned to the $T_{\text {true }}$ are merged to create a single crown object, and its pro-

Tab. 1 - Description of measured stand data in the reference plots (RP).

\begin{tabular}{lccccccc}
\hline Code & $\begin{array}{c}\text { Area } \\
\text { (ha) }\end{array}$ & $\begin{array}{c}\text { Number } \\
\text { of tree } \\
\text { species }\end{array}$ & $\begin{array}{c}\text { Conifers } \\
(\%)\end{array}$ & $\begin{array}{c}\text { Mean } \\
\text { height } \\
(\mathbf{m})\end{array}$ & $\begin{array}{c}\text { Mean } \\
\text { diameter } \\
(\mathbf{c m})\end{array}$ & $\begin{array}{c}\text { Volume } \\
\left(\mathbf{m}^{3} \mathbf{h a}^{-1}\right)\end{array}$ & $\begin{array}{c}\text { Slope } \\
(\%)\end{array}$ \\
\hline RP1 & 0.50 & 6 & 8 & 26.67 & 32.55 & 429.16 & 25 \\
RP2 & 0.30 & 6 & 43 & 27.27 & 34.73 & 611.49 & 33 \\
RP3 & 0.25 & 7 & 61 & 26.64 & 37.75 & 446.25 & 5 \\
RP4 & 0.25 & 5 & 73 & 32.72 & 43.57 & 622.12 & 6 \\
RP5 & 0.25 & 3 & 1 & 26.91 & 26.68 & 584.45 & 37 \\
RP6 & 0.25 & 3 & 80 & 27.31 & 44.31 & 617.80 & 22 \\
RP7 & 0.25 & 5 & 50 & 23.70 & 36.60 & 508.44 & 22 \\
RP8 & 1.00 & 6 & 75 & 28.59 & 43.37 & 507.18 & 25 \\
RP9 & 0.25 & 1 & 0 & 29.20 & 35.98 & 456.33 & 22 \\
Total & 3.30 & 11 & - & - & - & 4783.22 & - \\
Average & 0.37 & 5 & 43 & 27.67 & 37.28 & 531.47 & 22 \\
\hline
\end{tabular}

file is smoothed by Bezier interpolation. We found this method to well approximate the real $2 \mathrm{D}$ crown projection, allowing the fast processing of a large number of tree crowns. After the crown delineation phase is completed, the crown coverage is calculated as the ratio of the forest floor covered by the delineated vertical crown projection and the whole stand area.

Parameters used in the current study

We tested the effect of three tile sizes (TS $=1,2$ and $3 \mathrm{~m}$ ) on tree detection performance. A minimum tree height parameter was set with respect to the conventional forest definitions by IUFRO and FAO to 5 $\mathrm{m}$. Limits for geo-dendrometric test and crown delineation were estimated based on field sample data. The ratio of mean crown radius to tree height ( $\left.\mathrm{Cr}_{\text {mean }}\right)$ was set to 0.15 , the ratio of mean tree height differences to tree height ( $\left.\mathrm{hd}_{\text {mean }}\right)$ was 0.1 , the ratio of maximum crown width to tree height $\left(\mathrm{Cw}_{\max }\right)$ was 0.4 , and the ratio of maximum crown length to a tree height $\left(c l_{\max }\right)$ was set at 0.7.

\section{Data sources}

\section{Study area description}

The research was conducted in the Forest Enterprise of the Technical University in Zvolen, central Slovakia ( $48^{\circ} 37^{\prime} \mathrm{N}, 19^{\circ} 04^{\prime} \mathrm{E}$ - Fig. 4). The forest area covers 9964 ha and its prevalent aspects are south, east and south-west. The lowest elevation is at Jalná (280 $\mathrm{m}$ a.s.l.) and the highest at the Lavrín peak (1150 $\mathrm{m}$ a.s.l.). The territory includes oak, beech-oak, beech, fir-beech and spruce-fir-beech forest vegetation zones.

\section{ALS data}

The ALS data used to test the applicability of the presented workflow were acquired in April 2012 using a RIEGL Q680i scanner. The average flying altitude was $700 \mathrm{~m}$. The instrument operated at pulse rate frequency of $320 \mathrm{kHz}$, with a $122 \mathrm{~Hz}$ scan frequency and scan angle of \pm 50 degree. The obtained laser data covered the whole study area and had an average density of laser hits of 20 points per $\mathrm{m}^{2}$. From each emitted pulse, a maximum of seven returns were recorded. The point ratios were $56 \%$ for the first echo, $21 \%$ for the second, $13 \%$ for the third, and $10 \%$ for other echoes.

\section{Ground reference data}

The ground data were obtained by a terrestrial survey in a part of the study area. The survey was carried out in nine reference plots (RP) covering a total area of 3.3 ha (Fig. 4), which represented various relief and stand structure conditions (Tab. 1). The selected RP contained a range of terrain slopes, forest stands at different development stages, and vertical structures.

Most tree species occurring in the region were represented in the RPs. The species composition was dominated by Norway 
Fig. 5 - Detection rates of extracted (orange colour) and matched (blue colour) individual trees for the reference plots (RP1-9) and for different tile sizes (TS1, TS2,

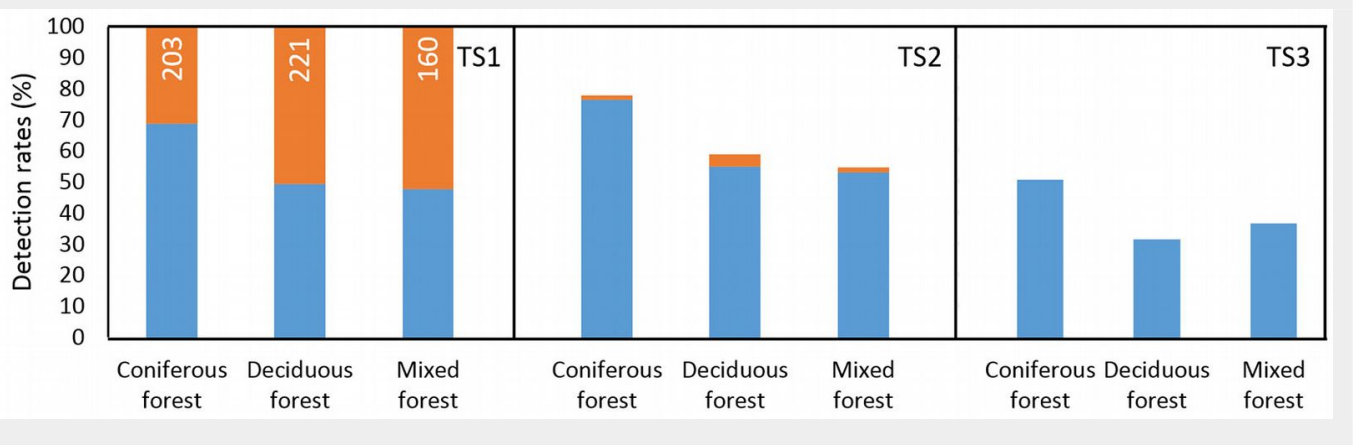

spruce (Picea abies L. Karst) with $42 \%$ coverage. Other conifers are Silver fir (Abies alba Mill.) with $13 \%$ and European larch (Larix decidua Mill.) with $0.1 \%$ coverage. Non-conifer species covered less than $45 \%$ of the forest area, and were dominated by European beech (Fagus sylvatica L.) with 34\%, Sessile oak (Quercus petraea Matusch) with 6\%, European hornbeam (Carpinus betulus L.) with $3 \%$ coverage, and other deciduous trees, which occurred in less than $2 \%$ of the forest area.

The crown canopy closure in the RP was between $78 \%$ and $100 \%$. Almost $70 \%$ of the measured trees were situated in the main crown level (co-dominant trees, constituting the main canopy), 20\% belonged to the upper level (dominant trees higher than the main canopy level) and $10 \%$ to the lower level (intermediate and suppressed trees lower than the main canopy).

A total of 1322 trees with diameter $\geq 7 \mathrm{~cm}$ were measured for position, species, height and diameter. The crown coverage in each RP was estimated as the proportion of forest floor covered by the estimated vertical projection of tree crowns.

\section{Accuracy assessment}

An accuracy assessment was carried out by comparing the ground reference data $\left(T E R_{i}\right)$ with outputs derived from the ALS data using the method described above $\left(A L S_{j}\right)$. The accuracy of both individual trees detection and crown coverage delineation was evaluated for three tile sizes $1 \times 1 \mathrm{~m}$ (TS1), $2 \times 2 \mathrm{~m}$ (TS2) and $3 \times 3 \mathrm{~m}$ (TS3).

Differences were calculated between $A L S_{j}$ and $T E R_{j}$ and the mean difference (eqn. 6 - see below) used as an indicator of systematic error (i.e., of under- or overestimation), and tested for significance. First, the normality of difference distribution was tested using the Shapiro-Wilk $W$ test to allow for a proper selection of the statistical test. If the differences were normally distributed, the Student's paired $t$-test was used $(\alpha=0.05)$ with $f=m-1$ degrees of freedom (mean difference test). If the differences were not normally distributed, the non-parametric paired Wilcoxon test was used $(\alpha=0.05)$ with $f=m-1$ degree of freedom (median difference test). The random error component (eqn. 7) was used to assess the dispersion of differences around the mean difference. The root mean square error (eqn. 8) was used to aggre- gate both the systematic and the random error components. The relative e\%, se\%, RMSE\% were calculated as the ratio of their absolute value and arithmetic average of the reference data (eqn. 6, eqn. 7 and eqn. 8).

$$
\begin{gathered}
e=\frac{\sum_{i=1}^{n} \hat{x}_{i}-x_{i}}{n} \\
s e=\sqrt{\frac{\sum_{i=1}^{n}\left(e_{i}-e\right)^{2}}{n}} \\
R M S E=\sqrt{\frac{\sum_{i=1}^{n}\left(\hat{x}_{i}-x_{i}\right)^{2}}{n}}
\end{gathered}
$$

where $e$ is the mean difference, se is the standard deviation of mean differences, $e_{i}$ is the individual difference, RMSE is the root mean square error, $n$ is the number of observation, $x_{i}$ and $\hat{x}_{i}$ are the ground-reference and ALS-derived attributes, respectively for the $i$-th tree.

The following detection rates were used to assess the ratio of detected individual trees and the reference trees: (i) the extraction rate (ER), as the total rate of detected trees (ALS) in respect to the number of reference trees in RP (TER - eqn. 9):

$$
E R=(A L S / T E R) \cdot 100
$$

(ii) the matching rate (MR), i.e., the total rate of matched trees (eqn. 10):

$$
M R=(T P / T E R) \cdot 100
$$

where TP indicates the true positives; (iii) the commission rate $(C R)$, i.e., the total rate of detected trees that could not be matched (eqn. 11):

$$
C R=(F P / A L S) \cdot 100
$$

where FP indicate the false positives; and (iv) the omission rate, i.e., the total rate of reference trees that could not be matched, according to Eysn et al. (2015 -eqn. 12).

$$
O R=(F N / T E R) \cdot 100
$$

where $\mathrm{FN}$ indicates the number of false negatives.

\section{Results}

The analysis of ground survey data revealed a number of treetops larger than that detected by the ALS-based assessment. Especially in densely forested areas, the detected local maxima do not always represent the exact tree positions, thus the matching rate was low. Trees that were standing alone, coniferous and clearly separated trees in loosely stocked areas were correctly detected in most instances.

\section{Accuracy of individual trees detection}

First, we evaluated the extraction and matching rates for the three forest types represented in the reference plots (coniferous, deciduous and mixed forest) and for three tile sizes (TS = 1, 2 and $3 \mathrm{~m}$ - Fig. 5). The bar graphs show that the optimal tiling size was $2 \times 2 \mathrm{~m}\left(\mathrm{TS}_{2}\right)$. This resolution produced the highest extraction and matching rates ( $68 \pm 14 \%$ and $65 \pm 14 \%$, respectively) with acceptable commission and omission rates ( $4 \pm 2 \%$ and $35 \pm 14 \%$, respectively).

The evaluation of differences in the number of individual trees detected by the proposed method and the number of reference trees on the ground suggested an overestimation using the tile size TS1 and an underestimation using tile size TS2 and TS3. The use of TS2 resulted in the highest accuracy, yielding an underestimation of $-34 \pm 15 \%$, with a RMSE $\%$ of $\pm 41 \%$. The mean or median paired test confirmed that the differences between number of field-measured and detected trees for each tile size were statistical significant $(p<0.05)$, i.e., the output of individual trees detection was significantly biased (Tab. 2).

We investigated the effect of the selected stand (in terms of tree species composition, number of tree species, mean height, mean diameter, and crown coverage), and site characteristics (slope) on the quality of the ALS-based tree detection (Fig. 6). A higher accuracy in the detection of individual trees was achieved in stands with a higher share of coniferous trees, as well as in stands with trees of greater dimensions (diameter and height) and higher social levels. A higher accuracy was also achieved in stands characterized by low relief slope, sparse crown canopy, and small number of tree species. However, this trend was significant $(p<0.05)$ only for canopy closure and mean stand diameter. Other parameters did not show any significant effect 
Tab. 2 - Differences and paired test between number of reference trees $\left(T E R_{n}\right)$ and detected trees $\left(\mathrm{ALS}_{\mathrm{n}}\right)$ for different tile size (TS1-3). (e\%): relative mean error; (se\%): relative standard deviation of mean error; (RMSE\%): relative root mean square error; $\left(^{*}\right)$ : null hypothesis is rejected $(p<0.05)$. Sample size: $m=9$.

\begin{tabular}{|c|c|c|c|c|c|c|c|}
\hline \multirow{2}{*}{$\begin{array}{l}\text { Compared } \\
\text { variables }\end{array}$} & \multirow{2}{*}{ e\% } & \multirow{2}{*}{ se\% } & \multirow{2}{*}{ RMSE\% } & \multicolumn{2}{|c|}{ Normality Test } & \multicolumn{2}{|c|}{ Paired Test } \\
\hline & & & & W & $\mathrm{p}$-value & $t$ or $Z$ & $\mathrm{p}$-value \\
\hline TER $_{n}$ vs. ALS $_{n \_T S 1}$ & 100 & 52 & 118 & 0.802 & $0.022^{*}$ & 2.666 & $0.008^{*}$ \\
\hline $\mathrm{TER}_{\mathrm{n}}$ vs. ALS $\mathrm{A}_{\mathrm{n}} \mathrm{TS} 2$ & -34 & 15 & 41 & 0.931 & 0.486 & 4.299 & $0.003^{*}$ \\
\hline $\mathrm{TER}_{\mathrm{n}}$ vs. $\mathrm{ALS}_{\mathrm{n}} \mathrm{TS} 3$ & -59 & 11 & 68 & 0.837 & 0.053 & 5.315 & $0.001^{*}$ \\
\hline
\end{tabular}

Tab. 3 - Reference crown coverage (TER $)$ and delineated crown coverage $\left(A L S_{c}\right)$ for the reference plots (RP1-9) and for different tile size (TS1-3).

\begin{tabular}{lccccccccccc}
\hline Variables & RP1 & RP2 & RP3 & RP4 & RP5 & RP6 & RP7 & RP8 & RP9 & Average & St. dev. \\
\hline TER $_{c}(\%)$ & 87 & 89 & 87 & 88 & 100 & 85 & 89 & 85 & 78 & 88 & 6 \\
ALS $_{\text {_CTS1 }}(\%)$ & 73 & 75 & 78 & 82 & 85 & 76 & 81 & 73 & 80 & 78 & 4 \\
ALS_CTS2 (\%) & 85 & 83 & 88 & 90 & 84 & 86 & 92 & 85 & 75 & 85 & 5 \\
ALS__TS3 (\%) & 94 & 91 & 96 & 98 & 97 & 94 & 96 & 93 & 93 & 95 & 2 \\
\hline
\end{tabular}

Tab. 4 - Differences and paired test between reference crown coverage $\left(T E R_{c}\right)$ and delineated crown coverage $\left(\mathrm{ALS}_{\mathrm{c}}\right.$ ) for different tile size (TS1-3). (e\%): relative mean error; (se\%): relative standard deviation of mean error; (RMSE\%): relative root mean square error; $\left({ }^{*}\right)$ : null hypothesis is rejected $(p<0.05)$. Sample size: $m=9$.

\begin{tabular}{|c|c|c|c|c|c|c|c|}
\hline \multirow{2}{*}{$\begin{array}{l}\text { Compared } \\
\text { variables }\end{array}$} & \multirow{2}{*}{$\mathrm{e} \%$} & \multirow{2}{*}{ se\% } & \multirow{2}{*}{ RMSE\% } & \multicolumn{2}{|c|}{ Normality Test } & \multicolumn{2}{|c|}{ Paired Test } \\
\hline & & & & W & p-value & $t$ or $Z$ & p-value \\
\hline $\mathrm{TER}_{\mathrm{c}}$ vs. $\mathrm{ALS}_{\mathrm{c} \_} \mathrm{TS} 1$ & -11 & 6 & 12 & 0.887 & 0.187 & 5.347 & $0.001^{*}$ \\
\hline $\mathrm{TER}_{\mathrm{c}}$ vs. $\mathrm{ALS}_{\mathrm{c} \_\mathrm{TS} 2}$ & -2 & 6 & 7 & 0.811 & $0.027^{*}$ & 0.770 & 0.441 \\
\hline $\mathrm{TER}_{\mathrm{c}}$ vs. $\mathrm{ALS}_{\mathrm{c}} \mathrm{TS} 3$ & 8 & 6 & 10 & 0.906 & 0.290 & -4.213 & $0.003^{*}$ \\
\hline
\end{tabular}

on the accuracy of tree detection.

Accuracy of crown coverage delineation

The crown coverage values obtained using the three alternative tile sizes (TS1, TS2 and TS3) are shown in Tab. 3, which also includes a ground-measured proportion of crown projections of the total area in the reference plots.

The proposed algorithm underestimated the crown coverage by $-11 \pm 6 \%$ with tile size TS1 and overestimated the crown coverage by $8 \pm 6 \%$ with tile size TS3. The RMSE $\%$ was $\pm 12 \%$ for TS 1 and $\pm 10 \%$ for TS 3 . As it was the case for the number of trees, the TS2 setting provided the best estimate of crown coverage, resulting in a slight underestimation $(-2 \pm 6 \%)$. The RMSE\% indicated that the crown cover was estimated with an accuracy of $\pm 7 \%$. Our analyses confirmed that different tile sizes significantly affect the accuracy of crown coverage delineation as well. At the same time, we found that only the TS2 setting provided the output that matched well with the ground measurements, however, this difference was not statistically significant (Tab. 4).

\section{Discussion}

In this study we explored the performance of a newly-developed point cloudbased algorithm for the detection of treetops and the delineation of tree crowns in a temperate mixed forest in Slovakia. We were particularly interested in evaluating the benefits of integrating customizable tree allometry information in the model for the detection of individual tree.

Although the accuracy of the proposed method did not exceed that reported by other researches (Vauhkonen et al. 2011b, Kaartinen et al. 2012, Koch et al. 2014), our study involves several innovations which might contribute to improve tree detection from ALD-derived data. In the following sections, we discuss the assets and limits of our results.

\section{Accuracy of tree detection}

Our findings indicated that the application of the developed algorithm using optimal settings can correctly capture approximately $65 \%$ of all trees in the study area. According to previous studies (Morsdorf et al. 2004, Kandare et al. 2016), the detection was less successful in stands with higher presence of deciduous species with closed crown canopy, due to their crown morphology with indistinct treetop. On the other hand, the crown projections were delineated with a very high accuracy $(-2 \pm$ $6 \%$ ) and the shape of delineated crowns represented the real $2 \mathrm{D}$ crown projection very well.

There are several factors which could have affected the accuracy of tree detection in our assessment, and which should

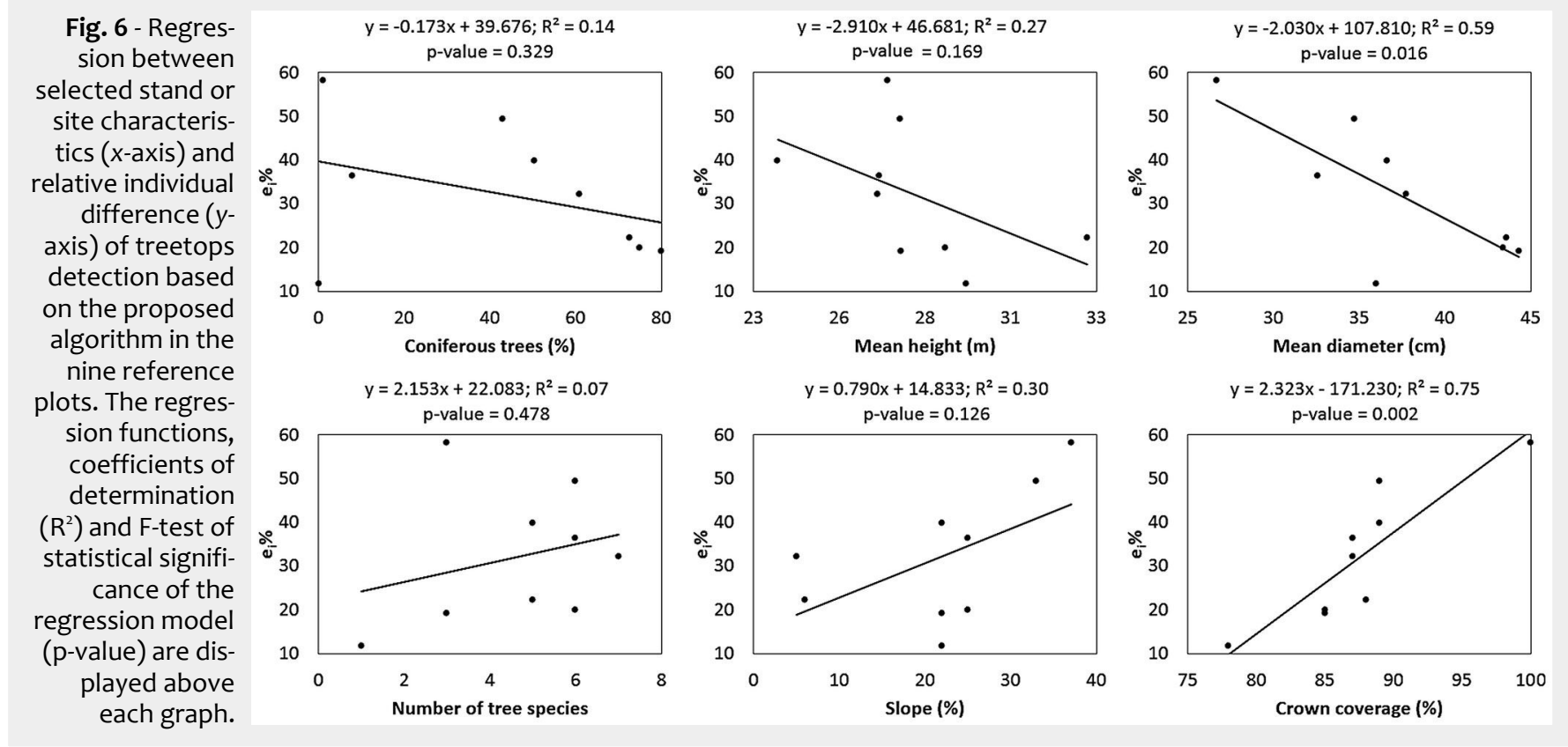


be considered when interpreting our findings. First, the RPs selected for the assessment included a broad range of site condition (including different tree species mixtures, stand density and relief slopes). This allowed the evaluation of the effect of site variables on tree detection accuracy. How ever, the selected RPs reflected a more complicated stand structure than commonly occurs in the study region, and this could have affected our results. Second, the geo-dendrometric criteria included into the tree position test decreased the number of detected trees, thus increasing the underestimation rate. On the other hand, such criteria reduced the false positive detections, thus preserving the permissible tree and stand structure and generating more realistic stands.

Although the accuracy of the proposed method suggests a limited applicability, the analysis of detected and undetected trees can provide a different perspective. The majority of undetected trees in the RPs had small size which poorly affects the assessment of the total stocking volume. Indeed, our previous research suggested that $32 \%$ of the undetected trees in the RPs contained only $11 \%$ of the growing stock (Smelko et al. 2014). Therefore, when the growing stock volume has to be assessed, an average tree detection rate of $65 \%$ might not be thought as limiting the use of the proposed algorithm.

Our results showed that the tile size had significant effect on the detection performance. We expect that testing the effect of a broader range of non-integer tile sizes could greatly improve the accuracy of the method, providing also a better adaptation to different stand structures and scanning densities (Kaartinen et al. 2012). Moreover, the inclusion of tree allometry criteria in the method allow to preserve the permissible stand and tree structure. Such criteria can be significantly improved by consider ing the specific morphometry of the dominant tree species, age classes and other tree and stand parameters. These parameters can be subjected to calibration based on measured data, thus improving tree detection performance with respect to particular stand conditions or specific mapping objectives.

The scanning density could affect tree detection performances as well. Kaartinen \& Hyyppä (2008), however, suggested that scanning density has a lower effect on tree detection that the extraction algorithm. In this study, we used a density of 20 hits per square meter, and we do not expect that an increase in scanning density could further improve the accuracy of detection of dominant and co-dominant trees. However, a higher scanning density could allow a deeper penetration through tree crowns, thus enhancing the detection of sup pressed trees growing under the canopy.

Additional improvement in the accuracy of tree detection can be attained by statistical correction of the results. In this study, a significant underestimation in the number of tree detected was observed and a bias correction could be applied. However, such correction should be applied with caution, particularly when the sample size is small, as it was the case of the current study.

\section{Comparison with other studies}

Unlike the proposed method, most studies used a canopy height model (CHM) as input for tree detection algorithms (Kania et al. 2014). Because such approach reduces the size of the initial point cloud, computational time and demands on hardware are reduced as well. On the other hand, part of the information supporting tree detection is lost by transforming the raw ALS data to a CHM. Consequently, a point-based approach was developed which retrieves a part of point cloud data linked with the crown segments, which were extracted from the CHM (Popescu \& Zhao 2008, Reitberger et al. 2009), or point cloud is directly used to detect the treetops (Vega et al. 2014, Ferraz et al. 2012). The former approach still requires processing ALS data to derive the CHM, while the latter approach might require time-consuming calculations. The algorithm proposed in this study was developed to compensate for such drawbacks. Specifically, the initial procedures optimize the number of points via tiling and height restriction operations. Subsequently, treetop detection and tree crown delineation are performed using the reduced and tiled point cloud in the original 3-dimensional data structure.

Most of the commonly used algorithms for tree detection from ALS-derived data consider all the local maxima detected as actual trees (Kankare et al. 2013, Yu et al. 2011). Contrastingly, our workflow applies an additional verification based on the presented geo-dendrometric criteria. Such criteria increase the probability that the local maxima represent real treetops rather than protruding branches, multiple terminals and other morphological patterns of tree crowns.

A distinctive feature of the developed algorithm is the crown delineation procedure. While other authors used mostly the CHM-based crown delineation (Eysn et al. 2015), our method detects each crown by gradually adding crown parts to the tree top and testing the match to the required dendrometric criteria at each iteration.

The tree detection accuracy attained in this study (65\%) is approximately in the middle of the range of tree detection accuracy $(40-93 \%)$ reported by Kaartinen et al. (2012) in an international benchmarking study. Moreover, in this study the accuracy of estimates of crown coverage was high $( \pm 7 \%)$, and within the range reported for similar studies (4-22\% - Holmgren et al. 2008). Furthermore, we found that the crowns delineated using the developed algorithm are morphologically similar to the $2 \mathrm{D}$ crown projection of field-measured trees. All the above evidences support the applicability of the proposed approach in evaluating forest tree and stand attributes.

\section{Conclusions}

ALS-based mapping of forest structure is an innovative component of forest inventory efforts, and has potential to significantly reduce the laborious field works and related costs.

We proposed a new method which integrate tree allometry criteria for detecting individual trees and delineating their crowns using ALS data. The method was validated using 1332 trees from 9 reference plots with heterogeneous stand structures. A significant underestimation rate in the accuracy of tree detection was obtained, while the accuracy of estimates of crown coverage was high and consistent with similar studies. Based on our findings we conclude that ALS-based forest inventory can provide reliable information only in particular stand conditions, specifically in commercial forests with simple structure, while their use in heterogeneous, vertically differentiated forests still remain limited.

The implementation of the proposed algorithm in the freely-available and easy-touse reFLex software is intended to support a broader use of ALS data and promote new researches aimed at improving the presented tree detection methods.

\section{Acknowledgments}

This research was supported by the Slovak Research and Development Agency, in the framework of the projects "Innovations in the forest inventories based on progressive technologies of remote sensing" (APVV-15-0393) and "Innovative methods of close-to-nature forests management" (APVV-0439-12).

\section{References}

Andersen HE, Strunk J, Temesgen H, Atwood D, Winterberger K (2011). Using multi-level remote sensing and ground data to estimate forest biomass resources in remote regions: a case study in the boreal forests of interior Alaska. Canadian Journal of Remote Sensing 37: 596611. - doi: 10.5589/m12-003

Bottalico F, Travaglini D, Chirici G, Marchetti M, Marchi E, Nocentini S, Corona P (2014). Classifying silvicultural systems (coppices vs. high forests) in Mediterranean oak forests by Airborne Laser Scanning data. European Journal of Remote Sensing 47: 437-46o. - doi: http:// www.tandfonline.com/doi/abs/10.5721/EuJRS20 144725

Ene L, Naesset E, Gobakken T (2012). Single tree in heterogeneous boreal forests using airborne laser scanning and area-based stem number estimates. International Journal of Remote Sensing 33: 5171-5193. - doi: 10.1080/01431161.20 12.657363

Eysn L, Hollaus M, Lindberg E, Berger F, Monnet JM, Dalponte $M$, Kobal M, Pellegrini M, Lingua E, Mongus D, Pfeifer N (2015). A benchmark of LiDAR-based single tree detection methods 
using heterogeneous forest data from the Alpine space. Forests 6: 1721-1747. - doi: 10.3390/ f6051721

Ferraz A, Bretar F, Jacquemoud S, Gonçalves G, Pereira L, Tomé M, Soares $P$ (2012). 3-D mapping of a multi-layered Mediterranean forest using ALS data. Remote Sensing of Environment 121: 210-223. - doi: 10.1016/j.rse.2012.01.020 Frank AU (2005). Map algebra extended with functors for temporal data. In: "Perspectives in Conceptual Modeling Akoka” (Liddle SW, Song IY eds). Springer-Verlag, Berlin, Heidelberg, Germany, pp. 194-207. - doi: 10.1007/11568346_ 22

Frazer GW, Magnussen S, Wulder MA, Niemann KO (2011). Simulated impact of sample plot size and co-registration error on the accuracy and uncertainty of LiDAR-derived estimates of forest stand biomass. Remote Sensing of Environment 115: 636-649. - doi: 10.1016/j.rse.2010.10. 008

Gupta S, Weinacker H, Koch B (2010). Comparative analysis of clustering-based approaches for 3-D single tree detection using airborne fullwave LiDAR data. Remote Sensing 2: 968-989. doi: $10.3390 /$ rs2040968

Heinzel J, Weinecker H, Koch B (2010). Priorknowledge based single tree extraction. International Journal of Remote Sensing 32: 49905020.

Hernandez-Marin S, Wallace AM, Gibson GJ (2007). Bayesian analysis of Lidar signals with multiple returns. Pattern Analysis and Machine Intelligence, IEEE Transactions on Pattern Analysis and Machine Intelligence 29: 2170-2180. doi: 10.1109/TPAMI.2007.1122

Hollaus M, Werner M, Roncat A, Pfeifer N, Briese $C$ (2014). Full-waveform airborne laser scanning systems and their possibilities in forest applications. In: "Forestry Application of Airborne Laser Scanning: Concept and Case Studies" (Maltamo M, Naesset E, Vauhkonen J eds). Springer Netherlands, Dordrecht, Netherlands, pp. 1-16. - doi: 10.1007/978-94-017-8663-8_3 Holmgren J, Johansson F, Olofsson K, Olsson H, Glimskär A (2008). Estimation of crown coverage using airborne laser scanning. In: Proceedings of the "SilviLaser 2008" (Hill RA, Suárez J eds). Edinburgh (Scotland, UK), 17-19 Sept 2008, pp. 11. [online] URL: http://geography. swan.ac.uk/silvilaser/papers/oral_papers/Forest ryApplications\&Inventory/Holmgren.pdf

Hyyppä J, Inkinen M (1999). Detecting and estimating attributes for single trees using laser scanner. The Photogrammetric Journal of Finland 16: 27-42.

Hyyppä J, Yu X, Hyyppä H, Hyyppä M, Holopainen $M$, Kukko A, Kaartinen $H$, Jaakkola $A$, Vaaja M, Koskinen J, Alho P (2007). Advances in forest inventory using Airborne Laser Scanning. Remote Sensing: 1190-1207. - doi: 10.3390/rs40 51190

Kaartinen H, Hyyppä J (2008). Tree Extraction. EuroSDR Project Report, Dublin, Ireland, pp. 60.

Kaartinen H, Hyyppä J, Yu X, Vastaranta M, Hyyppä $H$, Kukko A, Holopainen $M$, Heipke $C H$, Hirschmugl M, Morsdorf F, Pitkänen J, Popescu S, Solberg S, Wolf BM, Wu JCH (2012). An international comparison of individual tree detection and extraction using Airborne Laser Scan- ning. Remote Sensing 4: 950-974. - doi: 10.3390/ rs4040950

Kandare K, Orka HO, Chan JCW, Dalponte M (2016). Effects of forest structure and airborne laser scanning point cloud density on 3D delineation of individual tree crowns. European Journal of Remote Sensing 49: 337-359. - doi: 10.5721/EuJRS20164919

Kania A, Lindberg E, Schroiff A, Mücke W, Holmgren J, Pfeifer N (2014). Individual tree detection as input information for Natura 2000 habitat quality mapping. In: Proceedings of the "Remote Sensing and GIS for Monitoring Habitat Quality" (Pfeifer N, Zlinszky A eds). Vienna (AT), 24-25 September 2014. Vienna, Austria, pp. 3. [online] URL: http://rsgis4hq.geo.tuwien. ac.at/fileadmin/editors/RSGIS4HQ/proceedings/ RSGIS4HQ_Kania2.pdf

Kankare V, Vastaranta M, Holopainen M, Räty M, Yu X, Hyypä J, Hyppä H, Alho P, Viitala R (2013). Retrieval of forest aboveground biomass and stem volume with airborne scanning LiDAR. Remote Sensing 5: 2257-2274. - doi: 10.3390/rs5 052257

Koch B, Heyder U, Weinecker H (2006). Detection of individual tree crowns in airborne lidar data. Photogrammetric Engineering and Remote Sensing 4: 357-363. - doi: 10.14358/PERS. 72.4.357

Koch B, Kattenborn T, Straub CH, Vauhkonen J (2014). Segmentation of forest to tree objects. In: "Forestry Application of Airborne Laser Scanning: Concept and Case Studies" (Maltamo $M$, Naesset E, Vauhkonen J eds). Springer Netherlands, Dordrecht, Netherlands, pp. 1-16. doi: 10.1007/978-94-017-8663-8_5

Lähivaara T, Seppänen A, Kaipio JP, Vauhkonen J, Korhonen L, Tokola T, Maltamo M (2014). Bayesian approach to tree detection based on airborne laser scanning data. IEEE Transactions on Geoscience and Remote Sensing 52: 26902699. - doi: 10.1109/TGRS.2013.2264548

Lindberg E, Hollaus M (2012). Comparison of methods for estimation of stem volume, stem number and basal area from airborne laser scanning data in a hemi-boreal forest. Remote Sensing 4: 1004-1023. - doi: 10.3390/rs4041004 Longley PA, Goodchild MF, Maguire DJ, Rhind DW (2005). Geographic information systems and science ( $3^{\text {rd }}$ edn). John Wiley, Chichester, UK, pp. 560. [online] URL: http://books.google. com/books?id=toobg60wFPEC

Maltamo M, Packalén P, Peuhkurinen J, Suvanto A, Pesonen A, Hyyppä J (2007). Experiences and possibilities of ALS based forest inventory in Finland. In: Proceedings of the "ISPRS Workshop on Laser Scanning 2007 and SilviLaser 2007" (Rönnholm P, Hyyppä H, Hyyppä J eds). Espoo (Finland), 12-14 Sept 2007, pp. 9. [online] URL: http://www.researchgate.net/publication/ 228374430

Maltamo $M$, Packalén $P$, Suvanto $A$, Korhonen KT, Mehtätalo P (2009). Combining ALS and NFI training data for forest management planning: a case study in Kuortane, Western Finland. European Journal of Forest Research 128: 305-317. - doi: 10.1007/s10342-009-0266-6

Means JE, Acker SS, Fitt BJ, Renslow M, Emerson L, Hendrix CJ (2000). Predicting forest stand characteristics with airborne scanning lidar. Photogrammetry Engineering and Re- mote Sensing 66: 1367-1371. [online] URL: http://andrewsforest.oregonstate.edu/pubs/pd f/pub2821.pdf

Mikita T, Klimánek M, Cibulka M (2013). Evaluation of airborne laser scanning data for tree parameters and terrain modelling in forest environment. Acta Universitatis Agriculturae et Silviculturae Mendelianae Brunensis 61: 13391347. - doi: 10.11118/actaun201361051339

Morsdorf F, Meier E, Kötz B, Itten KI, Dobbertin $M$, Allgöwer B (2004). LIDAR-based geometric reconstruction of boreal type forest stands at single tree level for forest and wildland fire management. Remote Sensing of Environment 92: 353-362. - doi: 10.1016/j.rse.2004.05.013 Naesset E (1997). Estimating timber volume of forest stands using airborne laser scanner data. Remote Sensing of Environment 51: 246-253. doi: 10.1016/S0034-4257(97)00041-2

Packalén P, Maltamo M (2007). The k-MSN method for the prediction of species-specific stand attributes using airborne laser scanning and aerial photographs. Remote Sensing of Environment 109: 328-341. - doi: 10.1016/j.rse.2007. 01.005

Packalén P, Maltamo M (2008). The estimation of species-specific diameter distribution using airborne laser scanning and aerial photographs. Canadian Journal of Forest Research 38: 17501760. - doi: 10.1139/Xo8-037

Pirotti F (2010). Assessing a template matching approach for tree height and position extraction from lidar-derived canopy height models of Pinus pinaster stands. Forests 1: 194-208. doi: 10.3390/f1040194

Popescu SC, Zhao K (2008). A voxel-based lidar method for estimating crown base height for deciduous and pine trees. Remote Sensing of Environment 112: 767-7810. - doi: 10.1016/j.rse.20 07.06.011

Reitberger J, Schnörr C, Krzystek P, Stilla U (2009). 3D Segmentation of single trees exploiting full waveform LiDAR data. ISPRS Journal of Photogrammetry and Remote Sensing 64: 561-574. - doi: 10.1016/j.isprsjprs.2009.04. 002

Ruiz LA, Hermosilla T, Mauro F, Godino M (2014). Analysis of the influence of plot size and LiDAR density on forest structure attribute estimates. Forests 5: 936-951. - doi: 10.3390/f5050936 Salas C, Ene L, Gregoire TG, Naesset E, Gobakken $\mathrm{T}$ (2010). Modelling tree diameter from airborne laser scanning derived variables: a comparison of spatial statistics models. Remote Sensing of Environment 114: 1277-1285. - doi: 10.1016/j.rse.2010.01.020

Sheridan RD, Popescu SC, Gatziolis D, Morgan $\mathrm{CL}$, Ku NW (2015). Modelling forest aboveground biomass and volume using airborne LiDAR metrics and forest inventory and analysis data in the Pacific Northwest. Remote Sensing 7: 229-255. - doi: 10.3390/rs70100229

Swetnam TL, Falk DA (2014). Application of metabolic scaling theory to reduce error in local maxima tree segmentation from aerial LiDAR. Forest Ecology and Management 323: 158-167. doi: 10.1016/j.foreco.2014.03.016

Smelko S, Sebn V, Bosel'a M, Sačkov I, Kulla L (2014). New variants of methods for multi-purpose inventory and monitoring of forest ecosystems using progressive technologies. NLC- 
LVú Zvolen, Zvolen, Slovakia, pp. 368. [in Slovak]

Tiede D, Hoffmann C (2006). Process oriented object-based algorithms for single tree detection using laser scanning data. In: Proceedings of the "Workshop on 3D Remote Sensing in Forestry" (Koukal T, Schneider W ed). Vienna (Austria), 14-15 Feb 2006, pp. 5. [online] URL: http://www.researchgate.net/publication/2288 51631

Tuominen S, Pitkänen J, Balazs A, Korhonen KT, Hyvönen P, Muinonen E (2014). NFI plots as complementary reference data in forest inventory based on airborne laser scanning and aerial photography in Finland. Silva Fennica 48: article id. 983. - doi: 10.14214/sf.983

Vauhkonen J, Mehtätalo L, Packalén P (2011a). Combining tree height samples produced by airborne laser scanning and stand management records to estimate plot volume in Eucalyptus plantations. Canadian Journal of Forest Research 41: 1649-1658. - doi: 10.1139/x11-083
Vauhkonen J, Ene L, Gupta S, Heinzel J, Holmgren J, Pitkänen J, Solberg $S$, Wang $\mathrm{Y}$, Weinacker $\mathrm{H}$, Hauglin $\mathrm{KM}$, Lien $\mathrm{V}$, Packalén $\mathrm{P}$, Globaken T, Koch B, Naesset E, Tokola T, Maltamo $M$ (2011b). Comparative testing of single-tree detection algorithms under different types of forest. Forestry 85: 27-40. - doi: 10.1093/forestry /cpro51

Vauhkonen J, Maltamo M, McRoberts RE, Naesset E (2014). Introduction to forestry applications of airborne laser scanning. In: "Forestry Application of Airborne Laser Scanning: Concept and Case Studies" (Maltamo M, Naesset E, Vauhkonen J eds). Springer Netherlands, Dordrecht, Netherlands, pp. 1-16. - doi: 10.1007/97894-017-8663-8_1

Vega C, Hamrouni A, Mokhtari SE, Morel J, Bock J, Renaud JP, Bouvier M, Durrieu S (2014). PTrees: a point-based approach to forest tree extraction from lidar data. International Journal of Applied Earth Observation 33: 98-108. doi: 10.1016/j.jag.2014.05.001
Xu Q, Hou Z, Maltamo M, Tokola T (2014). Calibration of area based diameter distribution with individual tree based diameter estimates using airborne laser scanning. ISPRS Journal of Photogrammetry and Remote Sensing 93: 6575. - doi: 10.1016/j.isprsjprs.2014.03.005 Yao W, Krull J, Krzystek P, Heurich M (2014). Sensitivity analysis of $3 \mathrm{D}$ individual tree detection from LiDAR point clouds of temperate forests. Forests 5: 1122-1142. - doi: 10.3390/f5061122

Yu X, Hyyppä J, Vastaranta M, Holopainen M, Viitala R (2011). Predicting individual tree attributes from airborne laser point clouds based on random forests technique. ISPRS Journal of Photogrammetry and Remote Sensing 66: 2837. - doi: 10.1016/j.isprsjprs.2010.08.003

Zhang C, Zhou Y, Qiu F (2015). Individual tree segmentation from LiDAR point clouds for urban forest inventory. Remote Sensing 7: 7892-7913. - doi: 10.339o/rs70607892 